Systematic Review

\title{
A Systematic Review of Psychobiotic Interventions in Children and Adolescents to Enhance Cognitive Functioning and Emotional Behavior
}

\author{
Melissa Basso ${ }^{1}(\mathbb{D})$, Nicola Johnstone ${ }^{1, * \mathbb{D}}$, Paul Knytl $^{1}$, Arjen Nauta ${ }^{2}$, Andre Groeneveld ${ }^{2}$ \\ and Kathrin Cohen Kadosh ${ }^{1, *}$ \\ 1 Department of Psychological Sciences, School of Psychology, Faculty of Health and Medical Sciences, \\ University of Surrey, Guildford GU2 7XH, UK; m.basso@surrey.ac.uk (M.B.); p.knytl@surrey.ac.uk (P.K.) \\ 2 FrieslandCampina, 3818 LE Amersfoort, The Netherlands; arjen.nauta@frieslandcampina.com (A.N.); \\ andre.groeneveld@frieslandcampina.com (A.G.) \\ * Correspondence: nicola.johnstone@surrey.ac.uk (N.J.); k.cohenkadosh@surrey.ac.uk (K.C.K.); \\ Tel.: +44-(0)-1483-68-3968 (K.C.K.)
}

check for

updates

Citation: Basso, M.; Johnstone, N.; Knytl, P.; Nauta, A.; Groeneveld, A.; Cohen Kadosh, K. A Systematic Review of Psychobiotic Interventions in Children and Adolescents to

Enhance Cognitive Functioning and Emotional Behavior. Nutrients 2022, 14, 614. https://doi.org/ 10.3390/nu14030614

Academic Editor: Daniel Lamport

Received: 11 November 2021

Accepted: 21 January 2022

Published: 30 January 2022

Publisher's Note: MDPI stays neutral with regard to jurisdictional claims in published maps and institutional affiliations.

Copyright: () 2022 by the authors. Licensee MDPI, Basel, Switzerland. This article is an open access article distributed under the terms and conditions of the Creative Commons Attribution (CC BY) license (https:/ / creativecommons.org/licenses/by/ $4.0 /)$.

\begin{abstract}
This systematic review brings together human psychobiotic interventions in children and adolescents (aged 6-25 years) to evaluate the efficacy of pre- and probiotic supplements on stress, anxiety, and cognitive outcomes. Psychobiotic interventions in animal studies highlighted sensitivity to effects during development and maturation in multiple domains from emotion to cognitive processing. Several translational psychobiotic interventions in humans have been carried out to assess effects on emotion and cognition during childhood and into adulthood. The findings illustrate that there are limited consistent psychobiotic effects in developing human populations, and this is proposed to be due to heterogeneity in the trials conducted. Consequentially, it is recommended that three specific factors are considered in future psychobiotic trials: (1) Specificity of population studied (e.g., patients, developmental age), (2) specificity of intervention, and (3) homogeneity in outcome measures.
\end{abstract}

Keywords: psychobiotics; probiotics; prebiotics; children; adolescents; dietary interventions

\section{Introduction}

In the last decade, research has repeatedly highlighted the key role that gut microbiota play in regulating the brain, cognition, and subsequent behavior in mature adults [1-3] and in childhood and adolescence [4-6] The human gut microbiota is composed of bacteria, archaea, yeasts, viruses and protozoa [7] and the term "gut microbiome" specifically refers to the "the genes and genomes of the microbiota, as well as the products of the microbiota and the host environment" [8]; see also [9] for a critical discussion. The gut microbiota and human host act as a holobiont, codependent for survival and homeostatic balance [10-12]. This is an essential state for maintaining gastrointestinal and metabolic functions and brain and behavior regulation [1,13]. For example, humans' gut microbiota is shaped via diet choices [14], and the gut microorganisms reciprocally contribute to host physiology maturation and maintenance $[15,16]$.

Bidirectional communications between the gut and brain (the so-called gut-brain axis, GBA) [17-19] allow gut microbiota to regulate gene expression in the brain by inhibiting micro-RNA (miRNA) and messenger RNA (mRNA) translation [20]. The increased or decreased expression levels of many miRNAs reflect various pathophysiologic processes of diseases via the synthesis and release of neurotransmitters implicated in psychopathology, such as gamma-aminobutyric acid (GABA) and the precursor pool for serotonin, [21], as well as brain-derived neurotropic factor expression [22]. Neuroactive metabolites produced by bacteria directly interact with gut autonomic synapses [23], and ultimately modulate 
brain neurochemistry and behavior. Bacteria also act via the production of short-chain fatty acids (SCFAs) and peptidoglycan (PGN). SCFAs enter circulation and have widespread effects on the brain directly (e.g., [24]) and the mucosal immune system [25].

Evidence in animal models found gut microbiota influences initial brain development, including synaptogenesis and myelination of brain areas [4], and brain responsiveness and function across the lifespan [26]. Bacterial colonization in human infants begins at birth [27], and over several years diversifies in richness and functional capacity [28]. Gut microbiota composition continues to adapt during development, characterized by a relative abundance of genes that support functional and structural brain development, maturing into adulthood with genes that reflect the host state (e.g., in disease, there is a greater predominance of genes related to inflammation, obesity, or adiposity) [29].

To date, research has focused on characterizing microbe populations in health and disease to discover avenues for intervention [7,17,30-32]. Specifically, animal and human research has pointed towards the transitional period from mid-childhood to early adulthood (approximately 10-25 years) as a sensitive time window during which the microbiota gutbrain axis is fine-tuned [33]. This critical time window coincides with ongoing maturation and increased plasticity levels at the behavioral and brain levels [34-36], encompassing a period sensitive to developing mental health problems. Therein, the gut microbiome might be a key mediator between the environment and the developing brain via multiple pathways (Figure 1). As the gut microbiota is easily manipulated through diet and food supplements (e.g., prebiotics and probiotics), this represents a promising target for shaping the microbiota GBA, and thus for redirecting neurodevelopmental trajectories. Critically, this would be important for better cognitive functioning and well-being in development.

\section{Targeting the Microbiota Gut-Brain Axis to Improve Developmental Outcomes}

Microbial ecology is modified therapeutically via the intake of so-called psychobiotics to help reduce stress responses and symptoms of anxiety and depression [31,37,38], as well as to increase cognitive functioning [14,39]. The term psychobiotics refers to live cultures of beneficial gut bacteria (probiotics) or substrates from fibers (prebiotics) that enhance the growth and/or activity of indigenous beneficial intestinal bacteria, which can improve brain function [40,41].

Probiotic strains, including members of the genera Lactobacillus and Bifidobacterium, are enriched in some dairy/fermented products, whereas prebiotics are nondigestible substances that feed the gut microbiome [42,43], such as oligosaccharides found in in cereals, fruits, and vegetables [40]. Both pro- and prebiotics are also commercially available as supplements. Both affect emotional, cognitive, systemic, and neural measures of anxiety in healthy and clinical populations [44,45]; see also [46-48] for systematic reviews of the evidence in adults and young people. Importantly, if administered during childhood and adolescence, probiotics and prebiotics might optimally act on cognition, anxiety, and maladaptive stress responses $[49,50]$. To date, there are limited summaries interrogating the evidence for efficacy of psychobiotics to improve adaptive functioning in both children and young people across cognitive and emotional domains. Moreover, no systematic overview is available that looks at the effects of factors such as timing and dosage on the various outcome measures. 


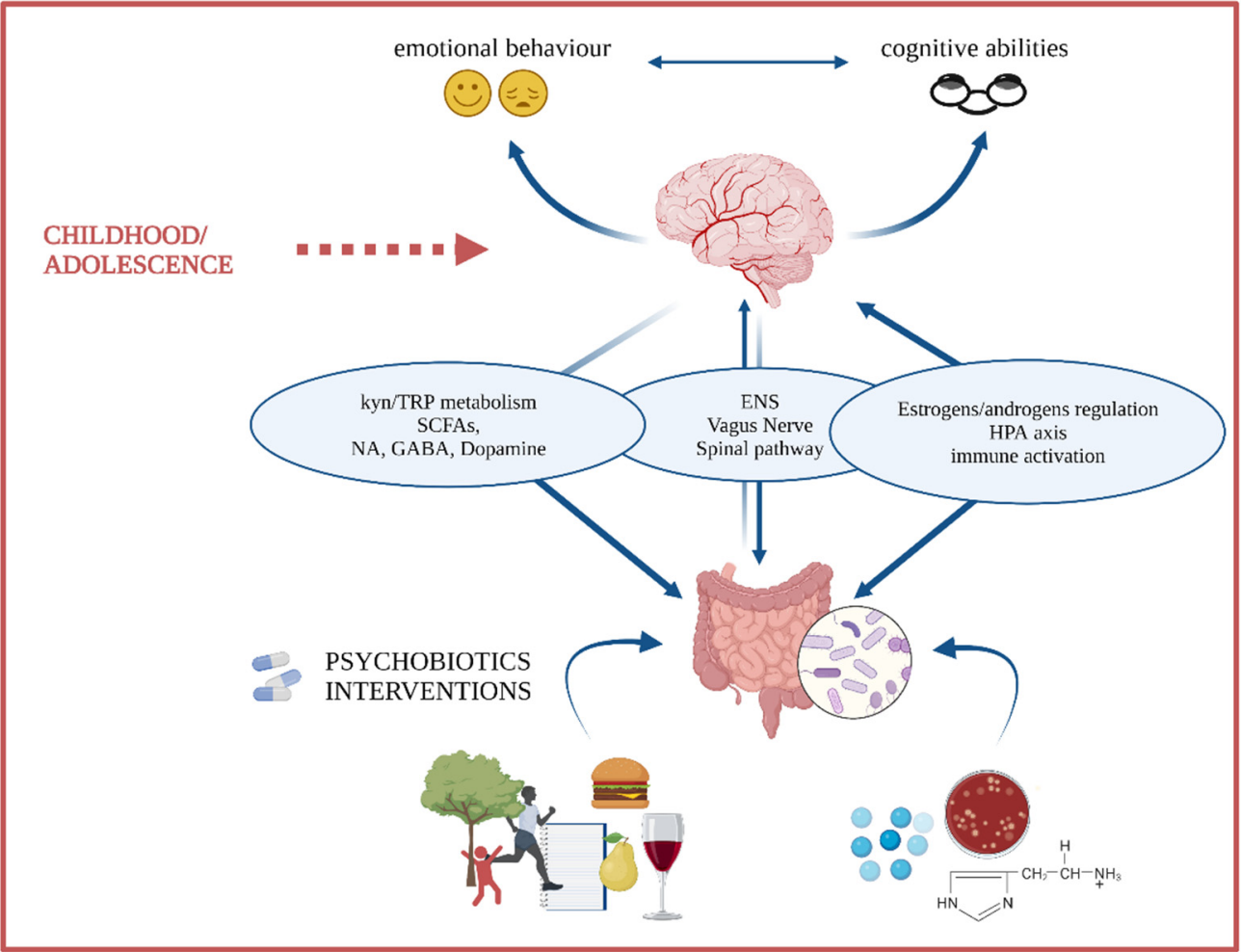

Figure 1. During childhood and adolescence, the individual is likely to undergo significant internal and external environmental changes and demands. At the same time, this is a time window when neuroplasticity is enhanced, allowing brain structures and circuitries to flexibly adapt or maladapt to the environment. In this context, gut microbiota might be a mediator between the environment and the CNS via multiple pathways that include: (i) the vagus nerve and spinal tract, whose action can be either direct or mediated by the ENS; (ii) the HPA axis; (iii) sex hormones (e.g., estrogens and androgens); (iv) microbes' production of proinflammatory compounds, which can lead to systemic inflammation and microglia activation; and (v) microbes' metabolites able to cross the BBB (e.g., SCFAs) and to alter the tryptophan/kynurenine pathways. Gut microbiota can be easily manipulated through diet; thus, it could be a promising therapy target in the redirection of neurodevelopmental trajectories.

\section{Objectives}

We systematically reviewed current evidence of psychobiotic interventions in children and adolescents to improve well-being and cognitive functioning to: (1) describe the efficacy of psychobiotics to influence and improve emotional well-being and cognitive functioning in childhood and adolescence, and (2) develop evidence-based recommendations for future research and intervention approaches.

\section{Methods}

\subsection{Protocol}

A systematic search was performed on trials in humans aged 6-25 years in which an active treatment (probiotics or prebiotics) and placebo were included. Primary outcomes were anxiety symptomatology and cognitive functions, and the secondary outcome was stress. The reporting of methods was consistent with the Preferred Reporting Items for Systematic Reviews and Meta-analyses (PRISMA) guidelines [51] and recommendations of the Cochrane Collaboration [52] (for the PRISMA checklist, see supplemental material). This protocol was registered on PROSPERO on 16 November 2020, accessible at https:/ / www.crd.york.ac.uk/PROSPERO/display_record.php?RecordID=213265 (accessed 1 November 2021). All materials and data collected were reported. 


\subsection{Eligibility Criteria}

Controlled trials assessing anxiety and/or stress, or cognition with at least one active treatment group and one comparator group in both subclinical and clinical populations were included. Inclusion criteria were: (1) mean age in the range of 6-25 years old, (2) healthy and clinical samples, (3) minimally measures obtained pre- and postintervention, (4) pro- or prebiotic administration in any form, (5) anxiety or cognition measured as primary or secondary outcomes with stress proxies also included when present, (6) employment of validated measurement instruments, (7) published and peer-reviewed data, and (8) any date of publication. Exclusion criteria were: (1) administration of a proand prebiotic combination (i.e., synbiotics) to avoid any confusion due to interaction effects (2) duplicate data/publications, and (3) unpublished data to ensure good research quality.

\subsection{Search Strategy, Study Selection, and Data Extraction}

Six databases were searched (PubMed, Embase, Cochrane, Scopus, Ovid, and Web of Science) between 18 and 27 October 2020 using the search terms reported in the supplemental material with no date of publication restrictions, in addition to hand-searching bibliographical articles associated with mental health. Searches for anxiety and/or stress and cognition were conducted in parallel, and outputs were imported into EppiReviewer4 V 4.11.5.3 [53], and duplicates were removed. Titles and abstracts were double screened before full-text articles were retrieved and screened. Spreadsheets were used to extract: (1) the first author's surname and the year of publication; (2) samples size, mean age, gender, and population; (3) type and length of intervention, dose, frequency, and delivery method; (4) comparator; (5) assessment methods of outcomes; and (6) outcome results as reported by the included studies. Authors were contacted when data were missing. Data were qualitatively synthesized as too heterogeneous to perform any statistical summary.

\subsection{Risk of Bias Assessment}

The Revised Cochrane risk-of-bias tool for randomization trials (RoB-2) [54] was used to consider the following bias domains: (1) random sequence generation (selection bias), (2) allocation concealment (selection bias), (3) personnel and participant blinding (performance bias), (4) outcome assessment blinding (detection bias), (5) incomplete outcome data (attrition bias), (6) selective reporting (reporting bias), and (7) other sources of bias.

\section{Results}

\subsection{Stress/Anxiety}

\subsubsection{Study Records}

The search identified 2618 relevant studies. After removal of 422 duplicates, 2196 abstracts and titles were double screened. Then, 2157 were excluded for ineligible samples, outcomes, or intervention, and 6 for text unavailability after request. A total of 33 full-text studies remained for eligibility assessment, of which 16 were excluded on either sample, outcome, or intervention. The final output was 17 studies-11 using probiotic interventions, and 6 using prebiotic interventions (Figure 2).

\subsubsection{Included Studies Characteristics}

A complete summary of study [55-71] characteristics is depicted in Table 1. Among the 11 studies that employed probiotics, a variety of species and strains were used: Saccharomyces boulardii, Lactobacillus casei Shirota, Lactobacillus plantarum DR7 or PS128, and Lactobacillus rhamnosus were administered singularly; or a combination of Lactobacilli, Bifidobacteria and/or Streptococcus. These were delivered either as capsules, powder, or sachets with a daily dose up to $1 \times 10^{11}$ colony-forming units (CFUs) and a length of intervention ranging from 14 to 56 days. Concerning probiotic, six studies were identified, and galacto-oligosaccharides (GOS) and fructooligosaccharides (FOS) were the most used, followed by omega-3-polyunsaturated fatty acids (PUFAs) and fermented ginseng (FG). Omega-3-polyunsaturated fatty acids (PUFAs) and fermented ginseng (FG) were 
included due to their prebiotic effect on the gut microbiome [72,73]. Total daily dosage ranged between 18 and $5500 \mathrm{mg}$, for a minimum of 8 to a maximum of 84 days. Fourteen studies included a healthy sample of participants (e.g., students), either under stress conditions $[57-61,63,64,67,71]$ or normal daily circumstances $[55,56,62,68,69]$. The included clinical populations were also highly heterogenous; that is, individuals were affected by anorexia nervosa [66], autism spectrum disorder (ASD) [65], or learning disabilities [70] with no anxiety diagnosis. Finally, a range of assessment tools were used to measure both anxiety (State-Trait Anxiety Inventory, Beck Anxiety Inventory, Child Behavior Checklist) and stress (cortisol, metanephrine, self-reported stress, heart rate), thus further contributing to the heterogeneity of the different constructs being studied.

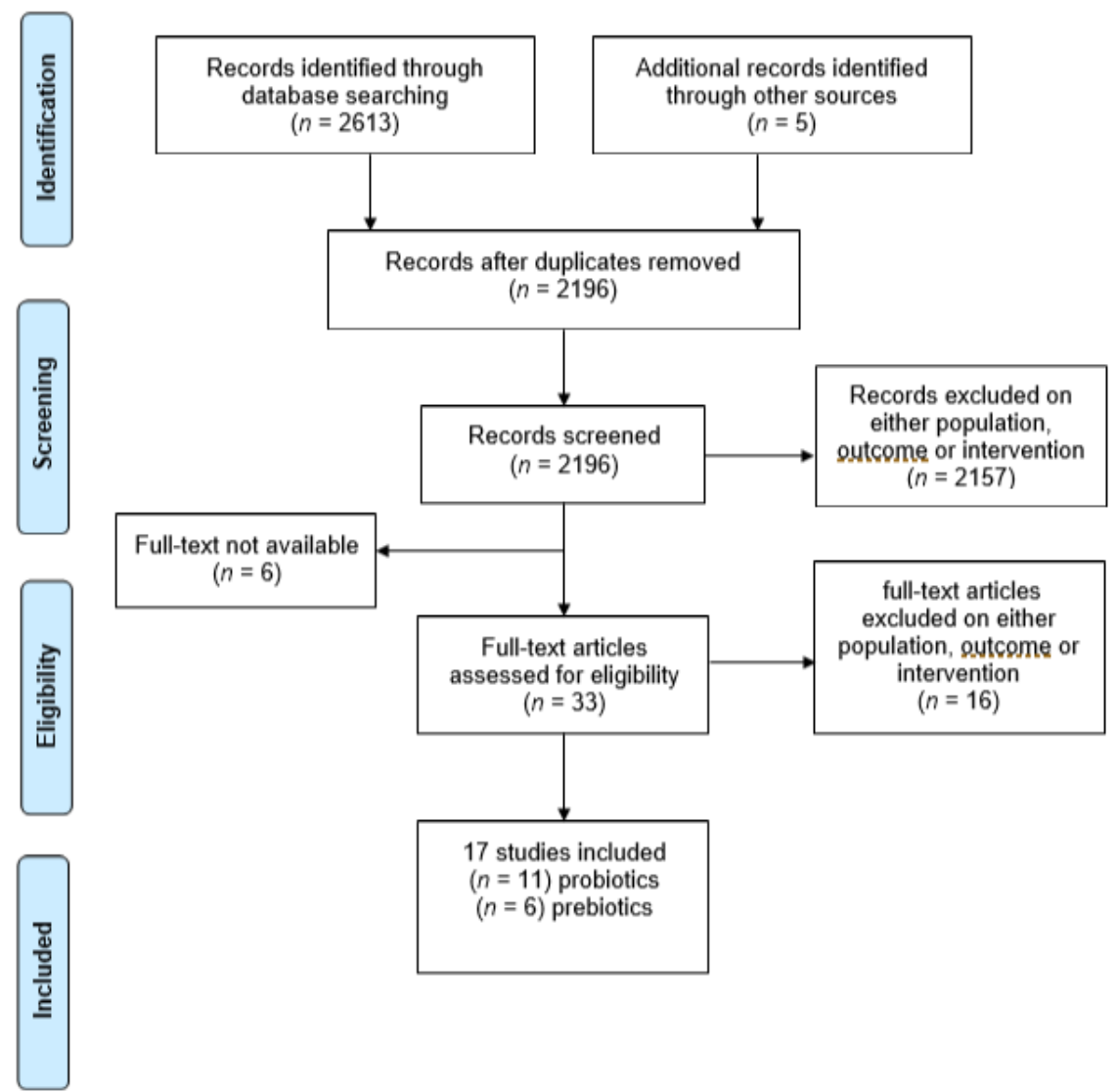

Figure 2. PRISMA flowchart of search results of each step of the review for anxiety/stress outcomes. 
Table 1. Characteristics of the anxiety/stress studies included in the systematic review.

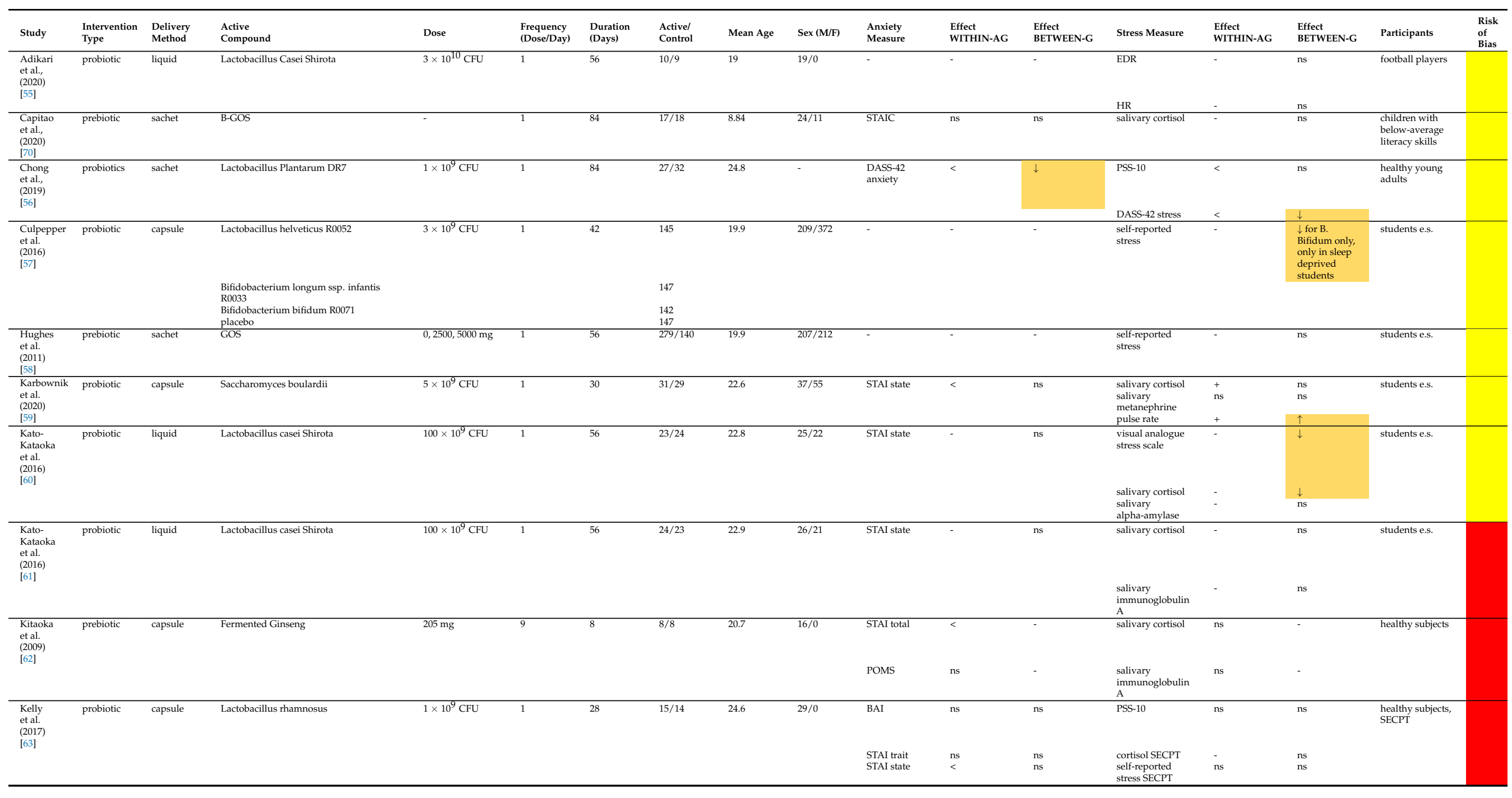


Table 1. Cont.

\begin{tabular}{|c|c|c|c|c|c|c|c|c|c|c|c|c|c|c|c|c|c|}
\hline Study & $\begin{array}{l}\text { Intervention } \\
\text { Type }\end{array}$ & $\begin{array}{l}\text { Delivery } \\
\text { Method }\end{array}$ & $\begin{array}{l}\text { Active } \\
\text { Compound }\end{array}$ & Dose & $\begin{array}{l}\text { Frequency } \\
\text { (Dose/Day) }\end{array}$ & $\begin{array}{l}\text { Duration } \\
\text { (Days) }\end{array}$ & $\begin{array}{l}\text { Active/ } \\
\text { Control }\end{array}$ & Mean Age & $\operatorname{Sex}(M / F)$ & $\begin{array}{l}\text { Anxiety } \\
\text { Measure }\end{array}$ & $\begin{array}{l}\text { Effect } \\
\text { WITHIN-AG }\end{array}$ & $\begin{array}{l}\text { Effect } \\
\text { BETWEEN-G }\end{array}$ & Stress Measure & $\begin{array}{l}\text { Effect } \\
\text { WITHIN-AG }\end{array}$ & $\begin{array}{l}\text { Effect } \\
\text { BETWEEN-G }\end{array}$ & Participants & $\begin{array}{l}\text { Risk } \\
\text { of } \\
\text { Bias }\end{array}$ \\
\hline 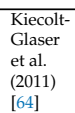 & prebiotic & capsule & omega-3 PUFAs & $2500 \mathrm{~g}$ & 1 & 84 & $34 / 34$ & 23.7 & $38 / 30$ & BAI & - & $\downarrow$ & - & - & - & students e.s. & \\
\hline $\begin{array}{l}\text { Manos } \\
\text { et al. } \\
(2018) \\
{[66]}\end{array}$ & prebiotic & capsule & omega-3-PUFAs & $782 \mathrm{mg}$ & 4 & 84 & $10 / 8$ & 14.7 & $0 / 18$ & BAIT & $<$ & $\uparrow$ & & - & - & anorexic girls & \\
\hline \multirow{2}{*}{$\begin{array}{l}\text { Marcos } \\
\text { et al. } \\
\text { (2004) } \\
{[770]}\end{array}$} & probiotic & 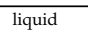 & $\begin{array}{l}\text { Lactobacillus delbrueckii bulgaricus } \\
\end{array}$ & $1 \times 10^{9} \mathrm{CFU}$ & 2 & 21 & $73 / 63$ & $18-23$ & $40 / 96$ & $\begin{array}{l}\text { STAI state } \\
\end{array}$ & + & $\mathrm{ns}$ & serum cortisol & - & $\mathrm{ns}$ & $\begin{array}{l}\text { students e.s. } \\
\text { s. }\end{array}$ & \\
\hline & & & $\begin{array}{l}\text { Streptococcus salivarius thermophilus } \\
\text { Lactobacillus casei DN114001 }\end{array}$ & $\begin{array}{l}10 \times 10^{9} \mathrm{CFU} \\
10 \times 10^{9} \mathrm{CFU}\end{array}$ & & & & & & STAI trait & & ns & & & & & \\
\hline \multirow{5}{*}{ 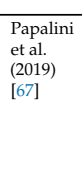 } & probiotic & powder & $\begin{array}{l}\text { Bifidobacterium bifidum W23, } \\
\text { Bifidobacterium lactis W51, }\end{array}$ & $2.5 \times 10^{9} \mathrm{CFU}$ & 2 & 28 & $29 / 29$ & 21.5 & $0 / 58$ & & & - & VAS & + & ns & $\begin{array}{l}\text { healthy subjects, } \\
\text { SECPT }\end{array}$ & \\
\hline & & & $\begin{array}{l}\text { Bifidobacterium lactis W52, Lactobacillus } \\
\text { acidophilus W37, Lactobacillus brevis }\end{array}$ & & & & & & & & & & & & & & \\
\hline & & & $\begin{array}{l}\text { W63, Lactobacillus casei W56, } \\
\text {, }\end{array}$ & & & & & & & & & & cortisol & + & ns & & \\
\hline & & & $\begin{array}{l}\text { Lactobacillus salivarius W24, Lactococcus } \\
\text { lactis W1, Lactococcus lactis W58 }\end{array}$ & & & & & & & & & & $\begin{array}{l}\text { alpha-amylase } \\
\mathrm{HR}\end{array}$ & + & $\begin{array}{c}\text { ns } \\
\text { ns }\end{array}$ & & \\
\hline & & & & & & & & & & & & & $\mathrm{BP}$ & + & ns & & \\
\hline \multirow{2}{*}{$\begin{array}{l}\text { Schmidt } \\
\text { et al. } \\
\text { (2015) } \\
{\left[\begin{array}{l}\text { (68] }\end{array}\right.}\end{array}$} & $\begin{array}{c}\text { prebiotic } \\
\end{array}$ & powder & FOS & $5500 \mathrm{mg}$ & 1 & 21 & 15 & 23.7 & $22 / 23$ & STAI state & & $\mathrm{ns}$ & PSS-10 & & ns & healthy subjects & \\
\hline & & & $\begin{array}{l}\text { B-GOS } \\
\text { placebo }\end{array}$ & & & & $\begin{array}{l}15 \\
15\end{array}$ & & & & & & salivary cortisol & - & $\downarrow$ GOS only & & \\
\hline \multirow{4}{*}{ 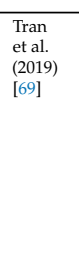 } & & & 10 species & $50 \times 10^{9} \mathrm{CFU}$ & & & 13 & & & & & - & & & & & \\
\hline & & & 18 species & $\begin{array}{l}\text { (condition B) } \\
15 \times 10^{9} \mathrm{CFU}\end{array}$ & & & 15 & & & PSWQ & & $\downarrow 50 \times 10^{9}$ & & & & & \\
\hline & & & 10 species & $\begin{array}{l}\text { (condition D) } \\
10 \times 10^{9} \mathrm{CFU}\end{array}$ & & & 15 & & & & & & & & & & \\
\hline & & & placebo & (condition E) & & & 11 & & & & & & & & & & \\
\hline
\end{tabular}

$\downarrow$ : Improvement vs. placebo; $\uparrow:$ diminishment vs. placebo; <: decrease vs. baseline; +: increase vs. baseline; ns: no significant effect; -: not reported or not applicable; dose refers to amount of active compound. FOS: fructooligosaccharides; B-GOS: Bimuno ${ }^{\circledR}$-galactooligosaccharides; PUFAs: polyunsaturated fatty acids; EDR: electrodermal activity; HR: heart rate DASS-42: Depression Anxiety Stress Scale 42; BP: blood pressure; BAI: Beck Anxiety Inventory; CBCL: Child Behavior Checklist (Anxiety); CFU: colony-forming unit; PASAT: Paced Auditory Serial Addition Test; PSS: Perceived Stress Scale-10; PSWQ: Penn State Worry Questionnaire; STAI: State-Trait Anxiety Inventory; STAIC: State-Trait Anxiety Inventory for Children; e.s.: under examination stress, VAS: visual analogue scale; PSS-10: perceived stress scale; SECPT: socially evaluated cold pressor test; POMS: profile of mood states; ASD: autism spectrum disorders. 


\subsubsection{Quality of the Included Studies}

Among the 17 included records, only 1 showed a low risk of bias [64], whereas 6 studies showed a high risk of bias $[60,62,63,66,69,71]$ (see Figure S1). Reasons for moderate concerns in study designs were mostly related to the absence of pre-specified protocols to compare with the published reports and the absence of detailed and clear information about the randomization process. Kelly and colleagues [63] were assessed at high risk of bias due to design, and neither described as blinded nor double blinded, in addition to absent information regarding intervention adherence and missing data. The high risk of bias for Kato-Kataoka and colleagues and colleagues [61] was due to the randomization process and significant differences in baseline State-Trait Anxiety Inventory (STAI) scores. Similar reasons applied to Kitaoka and colleagues and colleagues [63] and Manos and colleagues and colleagues [66], although baseline differences were not significant. Other reasons for a high risk of bias were lacking details about protocol adherence/deviations and inappropriate analyses to account for drops-out as well as, in the case of Marcos and colleagues and colleagues [70], concerns about the design, which was described as neither blinded nor double-blinded.

\subsubsection{Intervention Effects}

Four studies found significant results in anxiety or stress outcomes using a probiotic intervention. A 28-day multi-probiotic intervention significantly decreased worrying measured by the Penn State Worry Questionnaire (PSWQ) [62] whereas 84 days of L. plantarum administration led to improvements in the Depression Anxiety Stress Scale (DASS-42), both in anxiety and stress scores [56]. On the other hand, following L. casei Shirota intervention, no effects on anxiety were reported $[60,61]$ but were evident for stress assessed via a visual analogue scale (VAS) and cortisol levels [58]. Similarly, self-reported stress measures were shown to ameliorate after 42 days of supplementation with L. helveticus [57].

Regarding prebiotics, only two studies reported outcome improvements, a reduction in the Beck Anxiety inventory (BAI) scores following 84 days of omega-3 supplementation [64]; and second, decreased attentional bias towards negative emotion stimuli, accompanied by decreased cortisol levels after 21 days of GOS intervention [68]. It is worth mentioning that Kitaoka and colleagues [62] reported a within-group decrease in total anxiety scores following 8 days of fermented ginseng supplementation, although no information about group comparison was explicitly reported by the authors.

\subsection{Cognition}

\subsubsection{Study Records}

The search identified 1702 studies. After 304 duplicates were removed, 1398 abstracts and titles were double screened. 1360 were excluded for ineligible samples, outcomes, or intervention, and 1 for text unavailability. A total of 37 full-text studies remained for eligibility assessment, of which 18 were excluded on either sample, outcome, or intervention. The final output for the systematic review was 19 studies, 6 using probiotic interventions and 13 using prebiotic interventions (Figure 3).

\subsubsection{Included Studies' Characteristics}

A summary of study $[55,56,63,65,67,68,74-86]$ characteristics is depicted in Table 2. Among the six studies that employed probiotics, a variety of probiotic species and strains were used: Lactobacilli casei Shirota, Lactobacillus plantarum DR7, Lactobacillus plantarum PS128, and Lactobacillus rhamnosus, as well as a combination of Bifidobacterium bifidum W23, Bifidobacterium lactis W51, Bifidobacterium lactis W52, Lactobacillus acidophilus W37, Lactobacillus brevis W63, Lactobacillus casei W56, Lactobacillus salivarius W24, Lactococcus lactis W19, and Lactococcus lactis W58 (i.e., the Ecologic Barrier formula). Delivered using the same methods of the anxiety studies, probiotic dosages ranged between $1 \times 10^{9} \mathrm{CFU}$ and $3 \times 10^{10} \mathrm{CFU}$ administered once or twice a day, whereas the intervention length was between 28 and 84 days. In contrast, prebiotic supplementation used mostly PUFAs, such 
as docosahexaenoic acid (DHA) and eicosapentaenoic acid (EPA), with some using GOS or FOS. Total daily dosage ranged between $400 \mathrm{mg}$ [78] and $5500 \mathrm{mg}$ [68] for a minimum of 21 and a maximum of 121 days. Most probiotic studies were conducted on healthy participants, whereas prebiotics studies involved clinical samples, including children with attention-deficit hyperactivity disorder (ADHD), learning disabilities, and mood disorders. Cognitive functions measured included literacy, assessed by British Ability Scale-III; inhibition (e.g., go/no-go task), executive functions (e.g., Behavior Rating Inventory of Executive Functions), memory (e.g., digit span-forward/backward), cognitive reactivity (Leiden Index of Depression Sensitivity—revised) and attention (e.g., attentional dot-probe task).

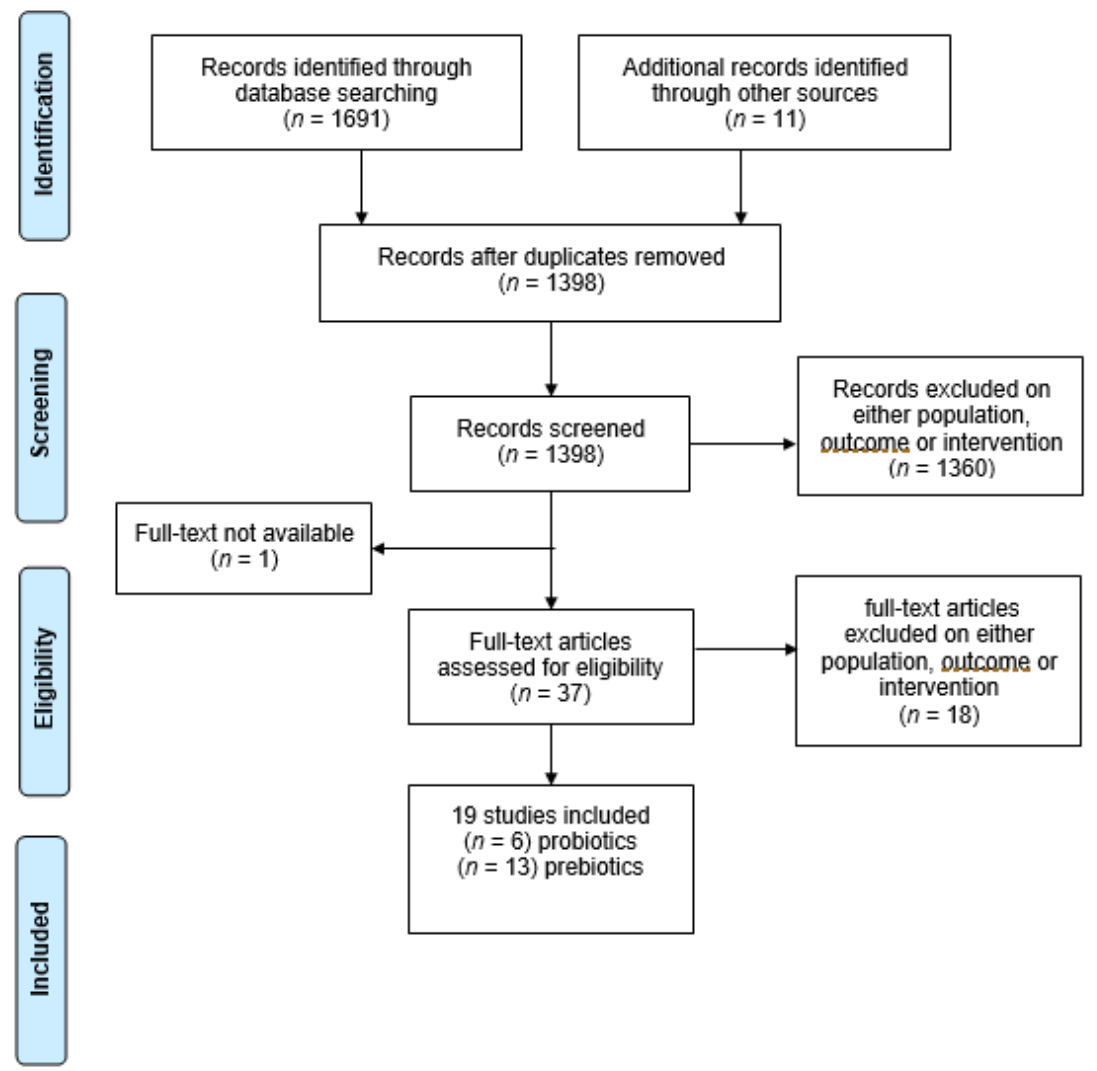

Figure 3. PRISMA flowchart of search results of each step of the review for cognitive outcomes. 
Table 2. Characteristics of the cognition studies included in the systematic review.

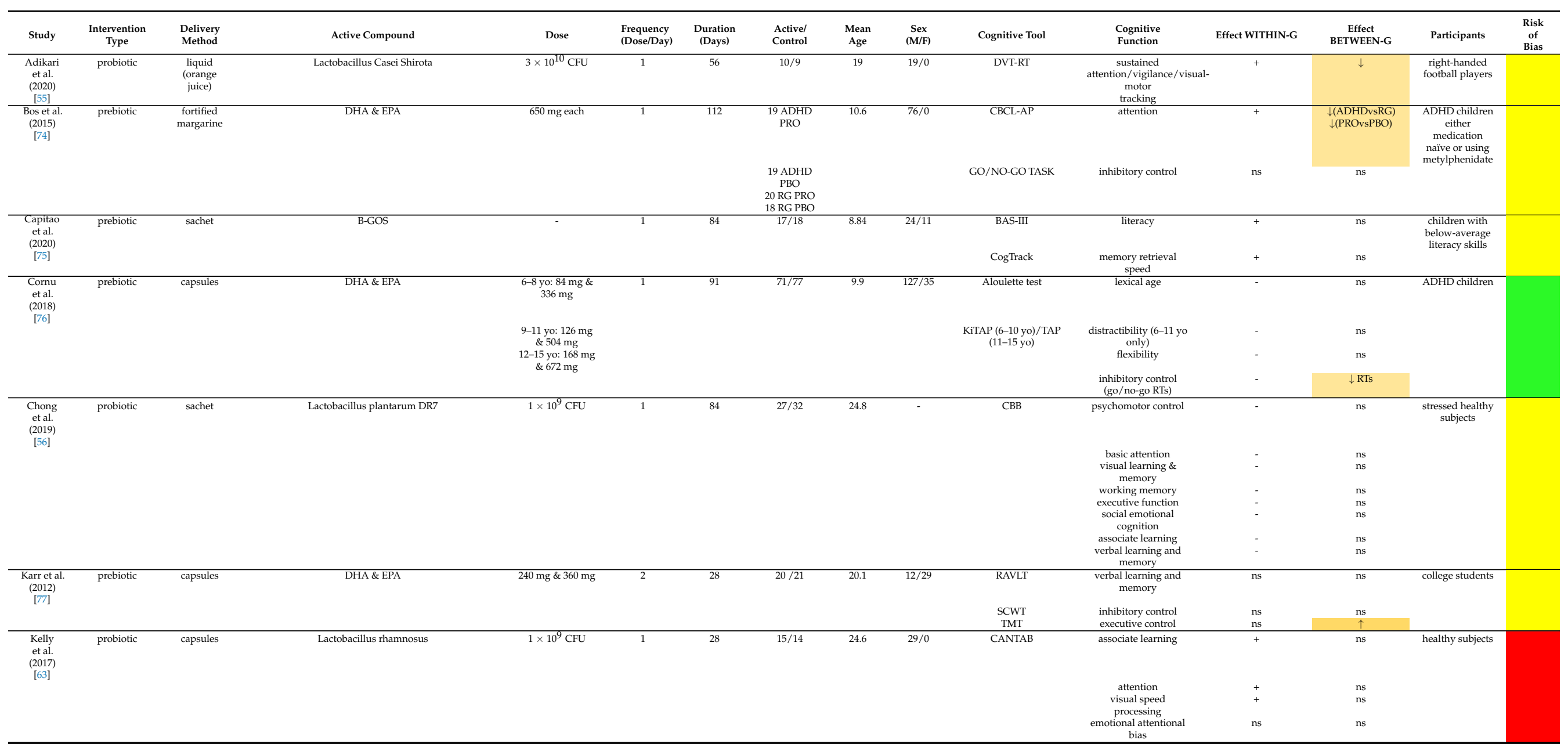


Table 2. Cont.

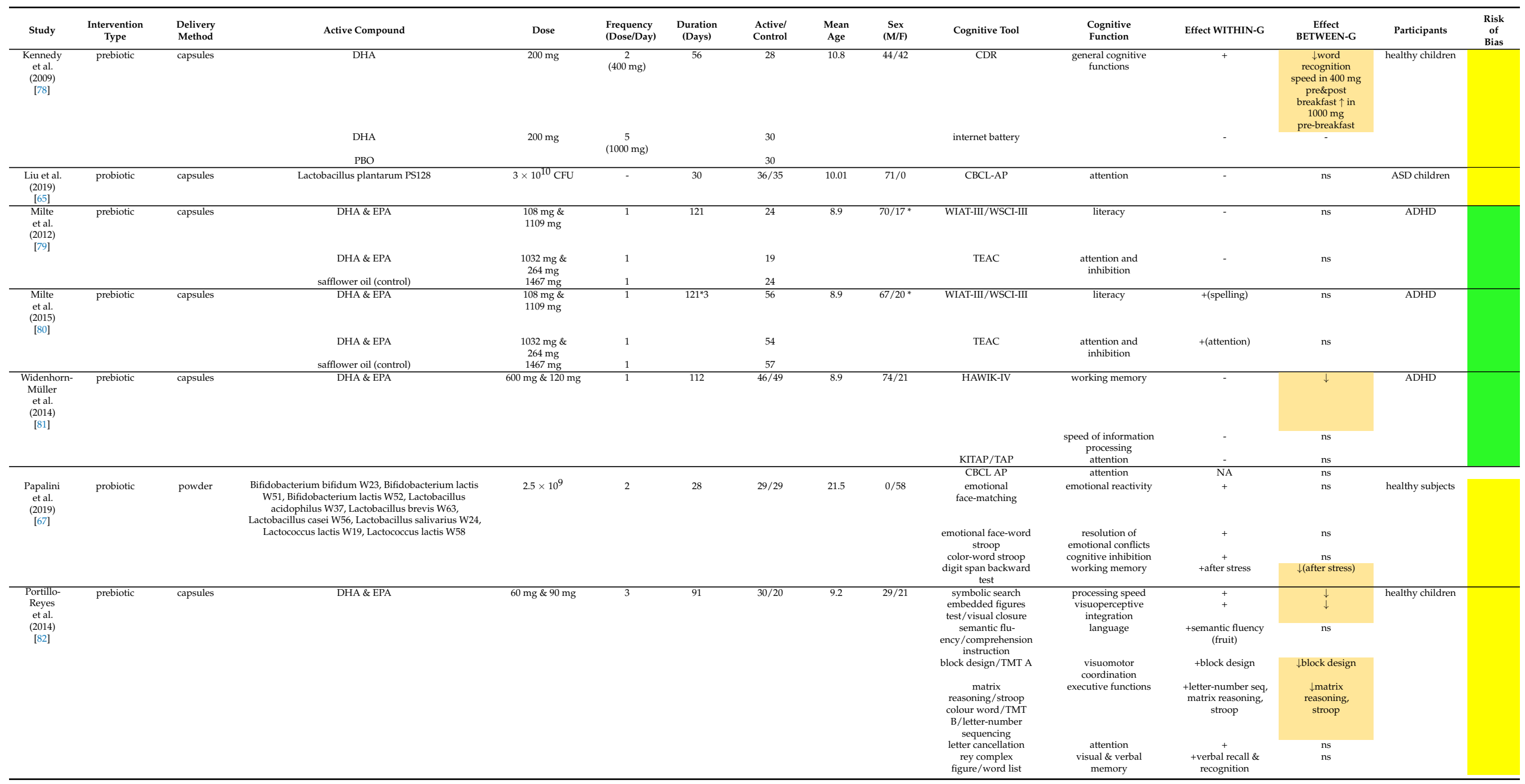


Table 2. Cont.

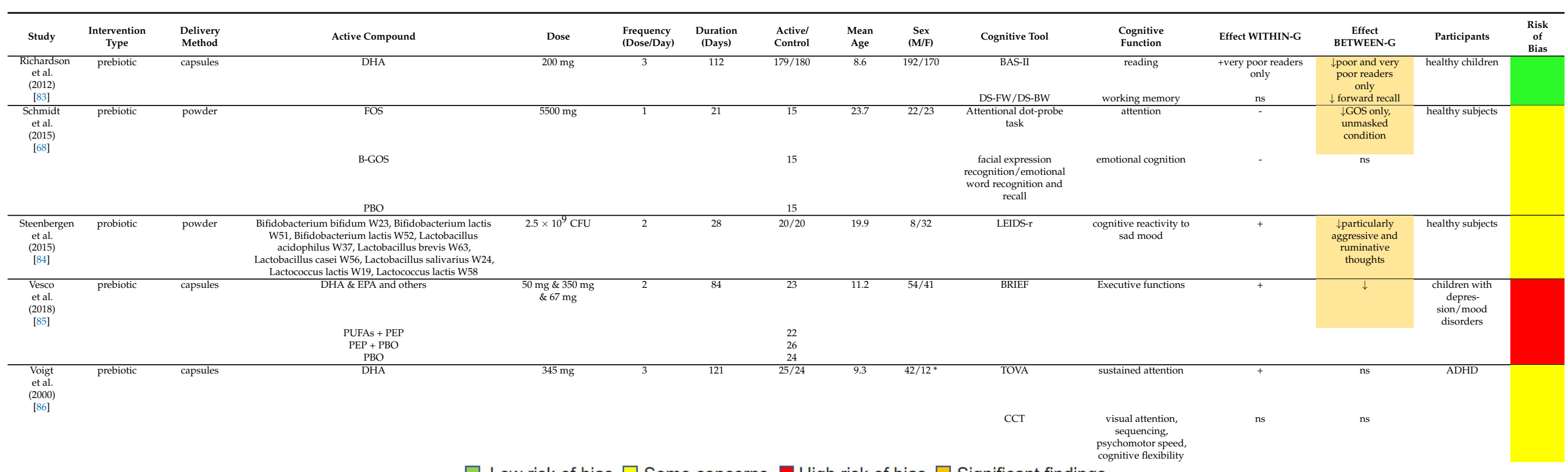

$\square$ Low risk of bias $\square$ Some concerns $\square$ High risk of bias $\square$ Significant findings

$\downarrow$ : Improvement vs. placebo; $\uparrow:$ diminishment vs. placebo; ns: no significant effect; $+:$ improvement of performance vs. baseline; -: not reported or not applicable; dose refers to the amount of active compound. DVT: digit vigilance test, RT: reaction times, DHA: docosahexaenoic acid; EPA: eicosapentaenoic acid; FOS: fructooligosaccharides; B-GOS: Bimuno $^{\circledR}$-galactooligosaccharides; PRO: probiotics; PBO: placebo; RG: reference group; CBCL-AP: Child Behavior Checklist-Attentional Problems; KiTAP: Test of Attentional Performance for Children; TAP: Test of Attentional Performance; CBB: Computerized CogState Brief Battery; RAVLT: Auditory Verbal Learning Test; SCWT: Stroop Color and Word Test; Performance for Children; TAP: Test of Attentional Performance; CBB: Computerized CogState Brief Battery; RAVLT: Auditory Verbal Learning Test; SCWT: Stroop Color and Word Test; TMT: Trial-Making Test; CANTAB: Cambridge Neuropsychological Test Automated Battery; CDR: Cognitive Drug Research Battery; WIAT: Wechsler Individual Achievement Test; DS-FW: digit-span forward; DS-BW: digit-span backward; LEIDS-r: Leiden Index of Depression Sensitivity-Revised; BRIEF: Behavior Rating Inventory of Executive Functions; TOVA: Test of Variables of Attention; CCT: Children's Colors Trials test. * As measured at baseline. 


\subsubsection{Quality of the Included Studies}

Among the 19 included records, 5 showed a low risk of bias [76,79-81,83] and 2 a high risk of bias $[63,85]$, while the remainder raised some concerns in bias (Figure S2). Reasons for moderate concerns in bias and high risk of bias in Kelly and colleagues and colleagues [63] were the same as reported for the anxiety studies. Additionally, the risk of bias for Vesco and colleagues and colleagues [85] was assessed as high due to the absence of justifications for the multiple imputation model in correcting for missing data in addition to an absence of reported baseline measures and a high probability that numerical results were selectively reported.

\subsubsection{Intervention Effects}

Only two out of six interventional studies using probiotics found significant effects. Specifically, following 56 days of L. casei Shirota administration, sustained attention was shown to improve in young football players, as indexed by a decrease in reaction times in the digit vigilance test [55]. This was in contrast to Liu and colleagues [65], who did not find any improvement in parental-reported attention scores in children affected by ASD. While both Chong and colleagues [56] and Kelly and colleagues [63] did not find any significant treatment effects, Papalini and colleagues [67] found improved working memory in the digit span-backward test following 28 days of a multispecies probiotic administration, although only under acute psychophysical stress. Notably, the same intervention ameliorated cognitive reactivity to sad mood in depressed participants [84].

Regarding prebiotics, 8 out of 13 studies reported significant results. Attention was shown to improve in Bos and colleagues [74] in ADHD participants following DHA and EPA administration, and in healthy participants under GOS supplementation [68]. In contrast, no attentional improvements were found in children with ADHD who were administered DHA only [86]. Heterogenous results were also found for inhibitory control measures, with significant improvement following 91 days of DHA and EPA administration in children with moderate ADHD [76], whereas no effects were found in ADHD children [74] nor in college students [77]. In contrast, in Karr and colleagues [77] the placebo group presented increased executive control. Studies investigating general cognitive functions $[78,82]$ showed positive effects of DHA and EPA combined and DHA alone in healthy participants, improved executive functions in children with mood disorders [85], and increased working memory scores in ADHD participants [81]. Concerning literacy, neither PUFAs nor GOS had consistent effects in ADHD participants [79,80], whereas Richardson and colleagues [83] reported improved reading scores in poor readers but otherwise healthy children.

\subsection{Overall Results}

Figure 4 maps efficacy in the available qualifying evidence. In most cases, prebiotic interventions were longer, delivered to subjects younger than 14 years of age, and targeted to improve cognition. In contrast, probiotics were mostly administered to young adults, with a shorter duration and a focus on improving anxiety and stress. Illustratively, there was limited evidence for psychobiotics' efficacy, and most positive responses to intervention were found for cognitive outcomes. 


\section{A. Prebiotic interventions}

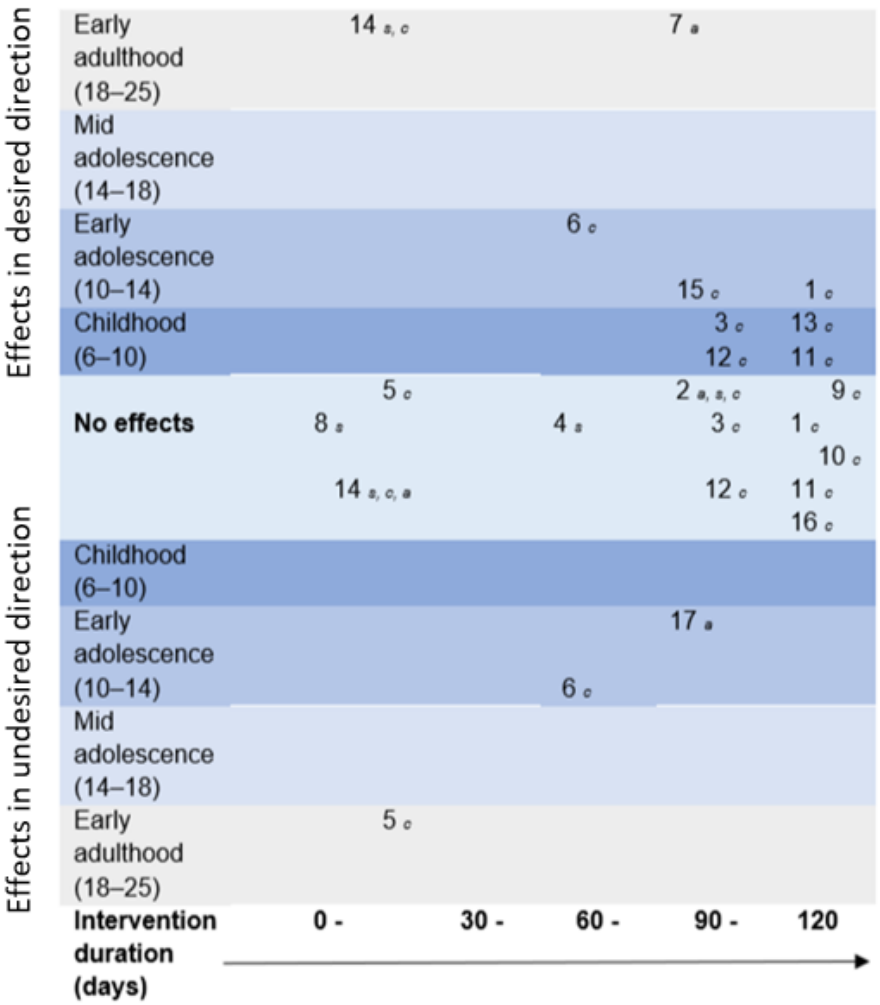

\section{B. Probiotic interventions}

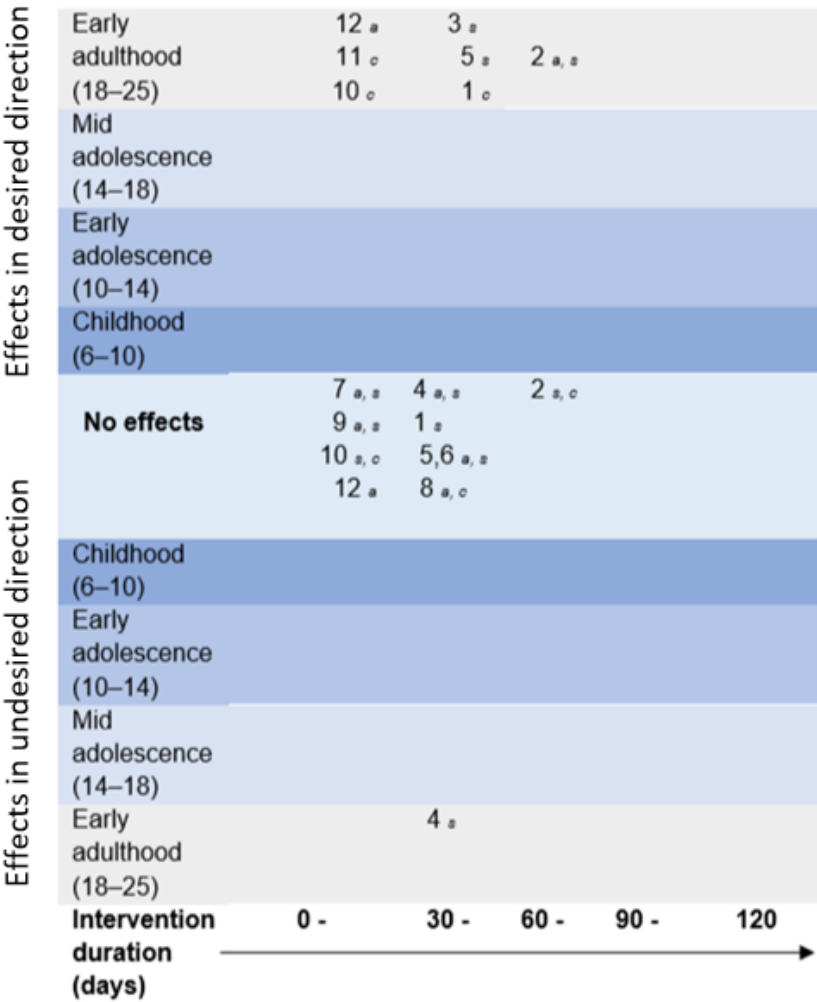

Figure 4. Mapping of systematic review outcomes by mean age of participant sample ( $x$-axis, numbers in brackets refers to the age range) and intervention duration ( $y$-axis) for each included study in which outcomes were categorized as effects in the desired direction (e.g., decreased anxiety, stress, or improved cognition vs. placebo), effects in the undesirable direction (e.g., increased anxiety, stress, or diminished cognitive effects vs. placebo), or no effects for pre- (A) and probiotic (B) interventions separately. Numbers in each panel refer to each specific study (indexed below), and letter subscripts refer to the categorical outcome (specified below). The key for each panel is as follows. (A). Studies using prebiotic interventions: ${ }^{1}[74],,^{2}[70],{ }^{3}[76], 4[58],{ }^{5}[77],{ }^{6}[78],{ }^{7}[64],{ }^{8}[62], 9[79],{ }^{10}[80],{ }^{11}[81]$, 12 [82], ${ }^{13}[83],{ }^{14}[68],{ }^{15}$ [85], ${ }^{16}$ [86], ${ }^{17}$ [66]. $a=$ anxiety outcome, $s=$ stress outcome, $c=$ cognition outcome. (B). Studies using probiotic interventions: ${ }^{1}$ [55], ${ }^{2}[56],{ }^{3}[57],{ }^{4}[59],{ }^{5}$ [60], ${ }^{6}$ [61], ${ }^{7}$ [63], 8 [65], ${ }^{9}$ [71], ${ }^{10}$ [67], ${ }^{11}$ [84], ${ }^{12}$ [69]. $a=$ anxiety outcome, $s=$ stress outcome, $c=$ cognition outcome.

\section{Discussion}

This systematic review aimed to describe the current evidence for the effectiveness of prebiotic- and probiotic-based interventions in the management of stress and anxiety, and in improving cognition in human children and adolescents, in addition to making recommendations for future research and intervention approaches. Based on the current findings, evidence available to support the use of psychobiotics for anxiety, stress, and cognition in therapeutic interventions in children and adolescents is minimal.

\subsection{Anxiety and Stress Findings}

From 17 eligible studies (11 probiotic), there is currently limited evidence for the efficacy of using probiotic and prebiotic interventions in alleviating anxiety and stress responses in children and adolescents. Several factors influenced this outcome; for example, heterogeneity in treatments, dosage, and duration rendered direct intervention comparisons difficult. Similarly, conceptualization of outcome measures varied across studies, complicating evaluation of anxiety and stress indices. This was further acerbated where full-texts or effect sizes (and raw data) were unavailable and not provided after request. Notably, whereas most studies used probiotic supplements for the intervention, 
two prebiotic studies (including PUFAs) (e.g., [64,68]) found effects on anxiety and stress measures, warranting further investigation. Specifically, as the reported effects might be underpinned by microbiota growth action and/or anti-inflammatory and immunomodulatory mechanisms, future human studies should use stool samples and biological proxies to better delineate PUFAs' mechanisms of action.

\subsection{Cognitive Findings}

A total of 19 eligible studies (13 prebiotic) evaluated cognitive outcomes. Therapeutic psychobiotic use for cognitive improvements in development is encouraging, with 50\% of studies reporting success. However, considerable variations in study design, intervention protocols, and participants sampled prevented a meta-analysis of the obtained effects. This was compounded by the range of cognitive functions investigated, including diverse measures in broad domains conceptualizing attention, executive functions, or working memory.

These results agreed with a recent systematic review and meta-analysis of pre- and probiotics and fermented foods on cognitive outcomes in human adults. Marx and colleagues [87] found more than half of eligible studies reported improved cognitive outcomes as a function of active intervention, yet this was not represented in the meta-analysis showing no detectable effects. Similarly, another systematic review of probiotic effects on cognition in all ages identified probiotic driven improvements in cognition in the majority of studies, yet highlighted problems in the quality of the studies [48]. Both studies commented on study quality, with problems in heterogeneity in clinical presentations, in addition to small samples and short-term interventions. These methodological issues were also present in younger age groups.

An observation on domain-specificity of psychobiotic intervention effects was drawn during this review; specifically, whether improvements in one domain (e.g., cognitive functions) would generalize to improvement in other measured domains (e.g., anxiety and/or stress). Several included studies facilitated this observation with the inclusion of both cognitive and anxiety/stress measures [55,56,63,65,67,68,70]. This subsample illustrated one occurrence of both cognitive and emotional improvements after 4 weeks of prebiotic supplement intake [68]. The remaining studies used probiotic interventions with emotional and cognitive measures, and found improvements in cognitive functions [55] or anxiety/stress indices [56] independently, or no improvements at all [63,65]. This observation suggested that prebiotic interventions might have a broader effect on overall functioning (domain general), whereas probiotic interventions may be more targeted in their effects. Mechanistic actions of pre- and probiotics largely overlap, and differentiating pathways to effects on the GBA in humans is further compounded by known external influences of the environment and dietary choices. More research is now needed to elucidate the utility of specific pre- and probiotic effects.

\subsection{Towards a More Standardized Research Approach in the Field of Psychobiotic Interventions}

A final objective of this study was the development of specific recommendations for future research. Based on the evidence reviewed, stringent standards are required to systematically advance this field. Key elements that must be considered are outlined in Figure 5. 
Specificity of effects in sample

\begin{tabular}{|c|c|c|c|}
\hline \multicolumn{4}{|c|}{ Target population } \\
\hline \multicolumn{2}{|c|}{ Clinical } & \multicolumn{2}{|c|}{ Sub-clinical } \\
\hline \multicolumn{4}{|c|}{ Gender } \\
\hline \multicolumn{2}{|l|}{ Male } & and/or & Female \\
\hline \multicolumn{4}{|c|}{ Age range } \\
\hline $\begin{array}{l}\text { Childhood } \\
6-10 \text { years }\end{array}$ & $\begin{array}{c}\text { Early } \\
\text { adolescence } \\
10-16 \\
\text { years }\end{array}$ & $\begin{array}{c}\text { Mid- } \\
\text { adolescence } \\
15-17 \\
\text { years }\end{array}$ & $\begin{array}{c}\text { Early adult } \\
18-25 \\
\text { years }\end{array}$ \\
\hline \multicolumn{4}{|c|}{ Specificity of intervention } \\
\hline \multicolumn{4}{|c|}{ Prebiotics } \\
\hline \multicolumn{2}{|c|}{ GOS/FOS } & \multicolumn{2}{|c|}{ DHA/PUFA } \\
\hline \multicolumn{4}{|c|}{ Probiotics } \\
\hline \multicolumn{2}{|c|}{ Single species } & and/or & Muiti-species \\
\hline \multicolumn{4}{|c|}{ Activation } \\
\hline \multicolumn{2}{|c|}{ Dose } & \multicolumn{2}{|c|}{ Duration } \\
\hline
\end{tabular}

Homogeneity in outcomes

\begin{tabular}{c} 
Anxiety \\
Self-report questionnaire \\
Clinical assessment \\
Stress \\
Heart rate \\
Blood pressure \\
Cortisol (salivary/serum) \\
Self-report questionnaire \\
Visual analogue scales \\
\hline Activation \\
Attention \\
Inhibitory control \\
Working memory \\
Executive control \\
Processing speed \\
Literacy \\
Emotional reactivity \\
Motor reactivity \\
Visual/verbal memory \\
Sensory integration \\
\hline
\end{tabular}

Figure 5. Key recommendations for future psychobiotic interventions, based on observations from this study. Recommendations can be considered in three broad aspects: specificity of effects in the sample selected, specificity of effects from the intervention, and homogeneity in outcomes. The broad wash of outcomes in psychobiotic intervention trials with human participants was due to heterogeneity in the trials conducted and the key variables highlighted here. For population level effects to be established, it is recommended that future trials situate research in consideration of sample, intervention, and outcome.

Apart from extending the research approach to both preclinical and clinical populations, the most important improvement is the adoption of a standardized intervention protocol in terms of dosage and intervention length for both probiotics and prebiotics deployed. For example, probiotic intervention dosages were similar across cognition and anxiety/stress studies (cognition: $1 \times 10^{9}-3 \times 10^{10} \mathrm{CFU}$; anxiety/stress: $1 \times 10^{9}-3 \times 10^{10} \mathrm{CFU}$ ), whereas prebiotic interventions varied in dosage, with cognition studies using a lower dosage (400-1467 mg, except for Schmidt and colleagues [68], which employed $5500 \mathrm{mg}$ ) in comparison to anxiety/stress studies $(1845-5500 \mathrm{mg}$ ). This could be related to the prevalence of PUFA administration within the cognitive domain, an active ingredient for which a lower dosage might be sufficient for efficacy in comparison to GOS.

Dosage requirements could differ by age; for example, children seem to not benefit from higher dosages (and intervention lengths) of DHA and EPA $[79,80,86]$ in comparison to young adults [77]. Based on these findings, the standardization of intervention protocols should be tailored to age/developmental differences to allow comparison across studies employing the same active ingredient (e.g., PUFAs), and across compounds (e.g., PUFAs and GOS).

We note that not all supplements labelled prebiotics in the current systematic review are currently recognized as prebiotics. Specifically, we included several studies that used 
DHAs and PUFAs to improve either cognitive or anxiety indices. The rationale for this approach was that research has shown that DHAs and PUFAs mechanistically have a prebiotic effect on the gut microbiome [72], and therefore operate as functional psychobiotics.

The target populations for psychobiotic interventions also needs to be considered; we have highlighted the potential for differential developmental effects, and this encapsulates neurodiversity as well. For example, children with neurodevelopmental disorders such as autism and ADHD frequently present with comorbid gastrointestinal problems. Psychobiotics (especially PUFAs) seem promising for improving outcomes in those with ADHD. High-quality studies in developing populations with clinical neurodevelopmental disorders might be particularly beneficial in improving gastrointestinal and cognitive and/or emotional outcomes.

Similarly, comparable intervention lengths would provide time for additional followup testing points to assess the longevity of the effects. Critically, attention should be paid to the fact that effects on anxiety seem to appear with longer interventions $[55,63]$ than stress $[57,60,68]$, suggesting that anxiety improvements might be secondary, or dependent on changes to the physiological equilibrium. Standardized protocols would allow direct comparison of the effectiveness of different prebiotics and probiotic strains, and provide the foundation for further customize therapeutic intervention protocols for different age groups and conditions. Additionally, it would be beneficial to include measures of gut microbiome composition at both baseline and postintervention time points (e.g., [44]) to assess whether the observed effects at the behavioral level can be linked to changes in the gut microbiome.

Moreover, given the reciprocal relationship of the gut microbiome and the human host, future studies should include additional measures of factors that have all been shown to influence both the gut microbiome and behavior, such as diet, sleep, and exercise. Comprehensive stakeholder engagement, such as focus group work with children, adolescents, and their parents, as reported in a recent study [46], may lead to the discovery of additional important factors that influence the success of these interventions. In addition, this important feedback from participants with lived experience of problems with cognitive functioning and/or emotional behavior will further help tailor intervention protocols to ensure high levels of treatment uptake and compliance.

Last, to aid with standardization and greater comparability of intervention effects across studies, it will be essential to work towards a greater agreement on behavioral measures and instruments for both cognitive and mental health indices. This is in line with current developments in the field of mental health research. For example, in June 2020, the National Institutes of Mental Health, USA, and the Wellcome Trust, UK (which are two of the largest funders for mental health research) announced plans for a more standardized mental health research approach [88]; see also [89] for a critical discussion.

\section{Conclusions}

To date, interventions on psychobiotic outcomes have shown some beneficial effects on anxiety, stress, and cognition via both prebiotic and probiotic intake; however, these were not consistent. This review illustrated that the inconsistency was due to heterogeneity in the trials conducted, and recommends consideration of three key factors in future psychobiotic trials: specificity of sample, specificity of intervention, and homogeneity in outcomes acquired. Further, it is recommended that psychobiotic interventions obtain metrics of gut microbiota composition and tangible factors relating to food intake and physical activity to help elucidate steering factors of psychobiotic effects. This is critical, as the term psychobiotics implies a proven effect of the pro- and prebiotic supplements on the gut microbiome and the brain; however, more research is required to draw out consistency in the effects. 
Supplementary Materials: The following are available online at https:/ / www.mdpi.com/article/ $10.3390 /$ nu14030614/s1, Figure S1. Risk of bias evaluation for studies using anxiety and stress outcomes. Figure S2. Risk of bias evaluation for studies using cognitive outcomes.

Author Contributions: Conceptualization, N.J., A.N., A.G. and K.C.K.; Data curation, M.B. and P.K.; Formal analysis, M.B. and P.K.; Funding acquisition, N.J. and K.C.K.; Investigation, M.B., P.K. and K.C.K.; Writing—original draft, M.B. and P.K.; Writing—review \& editing, N.J., A.N., A.G. and K.C.K. All authors have read and agreed to the published version of the manuscript.

Funding: This study was supported by research funds awarded to K.C.K. and N.J. by FrieslandCampina.

Institutional Review Board Statement: Not applicable.

Data Availability Statement: All data supporting the results of this study can be found within the manuscript and supplemental materials.

Conflicts of Interest: K.C.K. and N.J. received research funding from FrieslandCampina. A.N. and A.G. are current employees of FrieslandCampina. M.B. and P.K. report no biomedical financial interests or potential conflicts of interest.

$\begin{array}{ll}\text { Abbreviations } \\ \text { ADHD } & \text { Attention-deficit hyperactivity disorder } \\ \text { ASD } & \text { Autism spectrum disorder } \\ \text { BAI } & \text { Beck Anxiety Inventory } \\ \text { CFU } & \text { Colony-forming unit } \\ \text { CIs } & \text { Confidence intervals } \\ \text { DASS-42 } & \text { Depression Anxiety Stress Scale 42 } \\ \text { DHA } & \text { Docosahexaenoic acid } \\ \text { EPA } & \text { Eicosapentaenoic acid } \\ \text { FOS } & \text { Fructooligosaccharides } \\ \text { GABA } & \text { Gamma-aminobutyric acid } \\ \text { GBA } & \text { Gut-brain axis } \\ \text { GOS } & \text { Galactooligosaccharides } \\ \text { miRNA } & \text { Micro-RNA } \\ \text { mRNA } & \text { Messenger RNA } \\ \text { PGN } & \text { Peptidoglycan } \\ \text { PSWQ } & \text { Penn State Worry Questionnaire } \\ \text { PUFAs } & \text { Omega-3-polyunsaturated fatty acids } \\ \text { RoB-2 } & \text { Risk of bias tool for randomization trials } \\ \text { SCFAs } & \text { Short-chain fatty acids } \\ \text { STAI } & \text { State-Trait Anxiety Inventory } \\ \text { VAS } & \text { Visual Analogue Scale } \\ & \end{array}$

\section{References}

1. Cryan, J.F.; Dinan, T.G. Mind-altering microorganisms: The impact of the gut microbiota on brain and behaviour. Nat. Rev. Neurosci. 2012, 13, 701-712. [CrossRef] [PubMed]

2. Luna, R.A.; Foster, J. Gut brain axis: Diet microbiota interactions and implications for modulation of anxiety and depression. Curr. Opin. Biotechnol. 2015, 32, 35-41. [CrossRef] [PubMed]

3. Mayer, E.A. Gut feelings: The emerging biology of gut-brain communication. Nat. Rev. Neurosci. 2011, 12, 453-466. [CrossRef] [PubMed]

4. Heijtz, R.D. Fetal, neonatal, and infant microbiome: Perturbations and subsequent effects on brain development and behavior. Semin. Fetal Neonatal Med. 2016, 21, 410-417. [CrossRef] [PubMed]

5. Fung, T.C.; Olson, C.A.; Hsiao, E.Y. Interactions between the microbiota, immune and nervous systems in health and disease. Nat. Neurosci. 2017, 20, 145-155. [CrossRef]

6. de Weerth, C. Do bacteria shape our development? Crosstalk between intestinal microbiota and HPA axis. Neurosci. Biobehav. Rev. 2017, 83, 458-471. [CrossRef]

7. Methé, B.A.; Nelson, K.E.; Pop, M.; Creasy, H.H.; Giglio, M.G.; Huttenhower, C.; Gevers, D.; Petrosino, J.F.; Abubucker, S.; Mannon, P.J.; et al. A framework for human microbiome research. Nature 2012, 486, 215-221. [CrossRef] 
8. Arevalo, P.; Van Insberghe, D.; Elsherbini, J.; Gore, J.; Polz, M.F. A Reverse Ecology Approach Based on a Biological Definition of Microbial Populations. Cell 2019, 178, 820-834.e14. [CrossRef]

9. Berg, G.; Rybakova, D.; Fischer, D.; Cernava, T.; Vergès, M.-C.C.; Charles, T.; Chen, X.; Cocolin, L.; Eversole, K.; Corral, G.H.; et al. Microbiome definition re-visited: Old concepts and new challenges. Microbiome 2020, 8, 103. [CrossRef]

10. Rosenberg, E.; Zilber-Rosenberg, I. The hologenome concept of evolution after 10 years. Microbiome 2018, 6, 78. [CrossRef]

11. Zilber-Rosenberg, I.; Rosenberg, E. Role of microorganisms in the evolution of animals and plants: The hologenome theory of evolution. FEMS Microbiol. Rev. 2008, 32, 723-735. [CrossRef] [PubMed]

12. Margulis, L. Symbiosis as a Source of Evolutionary Innovation: Speciation and Morphogenesis. In Symbiogenesis and Symbionticism; Margulis, L., Fester, R., Eds.; MIT Press: Cambridge, MA, USA, 1991; pp. 1-14.

13. Bravo, J.A.; Forsythe, P.; Chew, M.V.; Escaravage, E.; Savignac, H.M.; Dinan, T.G.; Bienenstock, J.; Cryan, J.F. Ingestion of Lactobacillus strain regulates emotional behavior and central GABA receptor expression in a mouse via the vagus nerve. Proc. Natl. Acad. Sci. USA 2011, 108, 16050-16055. [CrossRef] [PubMed]

14. Magnusson, K.; Hauck, L.; Jeffrey, B.; Elias, V.; Humphrey, A.; Nath, R.; Perrone, A.; Bermudez, L. Relationships between diet-related changes in the gut microbiome and cognitive flexibility. Neuroscience 2015, 300, 128-140. [CrossRef] [PubMed]

15. Gensollen, T.; Iyer, S.S.; Kasper, D.L.; Blumberg, R.S. How colonization by microbiota in early life shapes the immune system. Science 2016, 352, 539-544. [CrossRef] [PubMed]

16. Sudo, N.; Chida, Y.; Aiba, Y.; Sonoda, J.; Oyama, N.; Yu, X.-N.; Kubo, C.; Koga, Y. Postnatal microbial colonization programs the hypothalamic-pituitary-adrenal system for stress response in mice. J. Physiol. 2004, 558, 263-275. [CrossRef]

17. Egrenham, S.; Clarke, G.; Cryan, J.F.; Dinan, T.G. Brain-Gut-Microbe Communication in Health and Disease. Front. Physiol. 2011, 2, 94. [CrossRef]

18. Grossman, M. Neural and Hormonal Regulation of Gastrointestinal Function: An Overview. Annu. Rev. Physiol. 1979, 41, 27. [CrossRef]

19. Mayer, E.A.; Knight, R.; Mazmanian, S.K.; Cryan, J.F.; Tillisch, K. Gut Microbes and the Brain: Paradigm Shift in Neuroscience. J. Neurosci. 2014, 34, 15490-15496. [CrossRef]

20. Oldham, M.C.; Konopka, G.; Iwamoto, K.; Langfelder, P.; Kato, T.; Horvath, S.; Geschwind, D.H. Functional organization of the transcriptome in human brain. Nat. Neurosci. 2008, 11, 1271-1282. [CrossRef]

21. Desbonnet, L.; Garrett, L.; Clarke, G.; Bienenstock, J.; Dinan, T.G. The probiotic Bifidobacteria infantis: An assessment of potential antidepressant properties in the rat. J. Psychiatr. Res. 2008, 43, 164-174. [CrossRef]

22. Caputo, V.; Sinibaldi, L.; Fiorentino, A.; Parisi, C.; Catalanotto, C.; Pasini, A.; Cogoni, C.; Pizzuti, A. Brain Derived Neurotrophic Factor (BDNF) Expression Is Regulated by Micro, RNAs mi, R-26a and mi, R-26b Allele-Specific Binding. PLoS ONE 2011, 6, e28656. [CrossRef] [PubMed]

23. Rhee, S.H.; Pothoulakis, C.; Mayer, E.A. Principles and clinical implications of the brain-gut-enteric microbiota axis. Nat. Rev. Gastroenterol. Hepatol. 2009, 6, 306-314. [CrossRef] [PubMed]

24. Silva, Y.P.; Bernardi, A.; Frozza, R.L. The Role of Short-Chain Fatty Acids from Gut Microbiota in Gut-Brain Communication. Front. Endocrinol. 2020, 11, 25. [CrossRef] [PubMed]

25. Spiljar, M.; Merkler, D.; Trajkovski, M. The Immune System Bridges the Gut Microbiota with Systemic Energy Homeostasis: Focus on TLRs, Mucosal Barrier, and SCFAs. Front. Immunol. 2017, 8, 1353. [CrossRef] [PubMed]

26. Luczynski, P.; McVey Neufeld, K.-A.; Oriach, C.S.; Clarke, G.; Dinan, T.G.; Cryan, J.F. Growing up in a Bubble: Using Germ-Free Animals to Assess the Influence of the Gut Microbiota on Brain and Behavior. Int. J. Neuropsychopharmacol. 2016, 19, pyw020. [CrossRef]

27. de Weerth, C.; Fuentes, S.; Puylaert, P.; de Vos, W.M. Intestinal Microbiota of Infants with Colic: Development and Specific Signatures. Pediatrics 2013, 131, e550-e558. [CrossRef]

28. Lynch, S.V.; Pedersen, O. The Human Intestinal Microbiome in Health and Disease. N. Engl. J. Med. 2016, 375, 2369-2379. [CrossRef]

29. Hollister, E.B.; Riehle, K.; Luna, R.A.; Weidler, E.M.; Rubio-Gonzales, M.; Mistretta, T.-A.; Raza, S.; Doddapaneni, H.V.; Metcalf, G.A.; Muzny, D.; et al. Structure and function of the healthy pre-adolescent pediatric gut microbiome. Microbiome 2015, 3, 36. [CrossRef]

30. Heijtz, R.D.; Wang, S.; Anuar, F.; Qian, Y.; Björkholm, B.; Samuelsson, A.; Hibberd, M.L.; Forssberg, H.; Pettersson, S. Normal gut microbiota modulates brain development and behavior. Proc. Natl. Acad. Sci. USA 2011, 108, 3047-3052. [CrossRef]

31. Burnet, P.W.; Cowen, P. Psychobiotics Highlight the Pathways to Happiness. Biol. Psychiatry 2013, 74, 708-709. [CrossRef]

32. Lloyd-Price, J.; Mahurkar, A.; Rahnavard, G.; Crabtree, J.; Orvis, J.; Hall, A.B.; Brady, A.; Creasy, H.H.; McCracken, C.; Giglio, M.G.; et al. Strains, functions and dynamics in the expanded Human Microbiome Project. Nature 2017, 550, 61-66. [CrossRef] [PubMed]

33. Neufeld, K.-A.M.; Luczynski, P.; Oriach, C.S.; Dinan, T.G.; Cryan, J.F. What's bugging your teen?-The microbiota and adolescent mental health. Neurosci. Biobehav. Rev. 2016, 70, 300-312. [CrossRef] [PubMed]

34. Johnson, M.H.; Grossmann, T.; Kadosh, K.C. Mapping functional brain development: Building a social brain through interactive specialization. Dev. Psychol. 2009, 45, 151-159. [CrossRef] [PubMed]

35. Johnson, M.H. Interactive Specialization: A domain-general framework for human functional brain development? Dev. Cogn. Neurosci. 2011, 1, 7-21. [CrossRef] [PubMed] 
36. Burnett, S.; Sebastian, C.; Kadosh, K.C.; Blakemore, S.-J. The social brain in adolescence: Evidence from functional magnetic resonance imaging and behavioural studies. Neurosci. Biobehav. Rev. 2011, 35, 1654-1664. [CrossRef]

37. Dinan, T.G.; Stanton, C.; Cryan, J.F. Psychobiotics: A Novel Class of Psychotropic. Biol. Psychiatry 2013, 74, 720-726. [CrossRef]

38. Tang, F.; Reddy, B.L.; Saier, M.H.S., Jr. Psychobiotics and Their Involvement in Mental Health. J. Mol. Microbiol. Biotechnol. 2014, 24, 211-214. [CrossRef]

39. Gareau, M. Cognitive Function and the Microbiome. Int. Rev. Neurobiol. 2016, 131, 227-246.

40. Boehm, G.; Jelinek, J.; Stahl, B.; Van Laere, K.; Knol, J.; Fanaro, S.; Moro, G.; Vigi, V. Prebiotics in Infant Formulas. J. Clin. Gastroenterol. 2004, 38, S76-S79. [CrossRef]

41. Gibson, G.R.; Scott, K.P.; Rastall, R.A.; Tuohy, K.M.; Hotchkiss, A.; Dubert-Ferrandon, A.; Gareau, M.; Murphy, E.F.; Saulnier, D.; Loh, G.; et al. Dietary prebiotics: Current status and new definition. Food Sci. Technol. Bull. Funct. Foods 2010, 7, 1-19. [CrossRef]

42. Barile, D.; Rastall, R. Human milk and related oligosaccharides as prebiotics. Curr. Opin. Biotechnol. 2013, 24, 214-219. [CrossRef] [PubMed]

43. David, L.A.; Maurice, C.F.; Carmody, R.N.; Gootenberg, D.B.; Button, J.E.; Wolfe, B.E.; Ling, A.V.; Devlin, A.S.; Varma, Y.; Fischbach, M.A.; et al. Diet rapidly and reproducibly alters the human gut microbiome. Nature 2014, 505, 559-563. [CrossRef] [PubMed]

44. Johnstone, N.; Milesi, C.; Burn, O.; Bogert, B.V.D.; Nauta, A.; Hart, K.; Sowden, P.; Burnet, P.W.J.; Kadosh, K.C. Anxiolytic effects of a galacto-oligosaccharides prebiotic in healthy females (18-25 years) with corresponding changes in gut bacterial composition. Sci. Rep. 2021, 11, 8302. [CrossRef] [PubMed]

45. Tillisch, K.; Labus, J.; Kilpatrick, L.; Jiang, Z.; Stains, J.; Ebrat, B.; Guyonnet, D.; Legrain-Raspaud, S.; Trotin, B.; Naliboff, B.; et al. Consumption of Fermented Milk Product with Probiotic Modulates Brain Activity. Gastroenterology 2013, 144, 1394-1401.e4. [CrossRef]

46. Kadosh, K.C.; Basso, M.; Knytl, P.; Johnstone, N.; Lau, J.Y.F.; Gibson, G.R. Psychobiotic interventions for anxiety in young people: A systematic review and meta-analysis, with youth consultation. Transl. Psychiatry 2021, 11, 352. [CrossRef]

47. Liu, X.; Cao, S.; Zhang, X. Modulation of Gut Microbiota-Brain Axis by Probiotics, Prebiotics, and Diet. J. Agric. Food Chem. 2015, 63, 7885-7895. [CrossRef]

48. Eastwood, J.; Walton, G.; Van Hemert, S.; Williams, C.; Lamport, D. The effect of probiotics on cognitive function across the human lifespan: A systematic review. Neurosci. Biobehav. Rev. 2021, 128, 311-327. [CrossRef]

49. Johnstone, N.; Kadosh, K.C. Why a developmental cognitive neuroscience approach may be key for future-proofing microbiotagut-brain research. Behav. Brain Sci. 2019, 42, 73. [CrossRef]

50. Murray, E.; Sharma, R.; Smith, K.B.; Mar, K.D.; Barve, R.; Lukasik, M.; Pirwani, A.F.; Malette-Guyon, E.; Lamba, S.; Thomas, B.J.; et al. Probiotic consumption during puberty mitigates LPS-induced immune responses and protects against stress-induced depression- and anxiety-like behaviors in adulthood in a sex-specific manner. Brain Behav. Immun. 2019, 81, 198-212. [CrossRef]

51. Shamseer, L.; Moher, D.; Clarke, M.; Ghersi, D.; Liberati, A.; Petticrew, M.; Shekelle, P.; Stewart, L.A. Preferred reporting items for systematic review and meta-analysis protocols (PRISMA-P) 2015: Elaboration and explanation. BMJ 2015, 349, g7647. [CrossRef]

52. Higgins, J.; Thomas, J.; Chandler, J.; Cumpston, M.; Li, T.; Page, M.; Welch, V. Cochrane Handbook for Systematic Reviews of Interventions. Available online: www.training.cochrane.org/handbook (accessed on 14 December 2021).

53. Thomas, J.; Graziosi, S.; Brunton, J.; Ghouze, Z.; O'Driscoll, P.; Bond, M. EPPI-Reviewer: Advanced Software for Systematic Reviews, Maps and Evidence Synthesis; UCL Social Research Institute: London, UK, 2020.

54. Sterne, J.A.C.; Savović, J.; Page, M.J.; Elbers, R.G.; Blencowe, N.S.; Boutron, I.; Cates, C.J.; Cheng, H.Y.; Corbett, M.S.; Eldridge, S.M.; et al. Ro, B 2: A revised tool for assessing risk of bias in randomised trials. BMJ 2019, 366, 14898. [CrossRef] [PubMed]

55. Adikari, A.; Appukutty, M.; Kuan, G. Effects of Daily Probiotics Supplementation on Anxiety Induced Physiological Parameters among Competitive Football Players. Nutrients 2020, 12, 1920. [CrossRef] [PubMed]

56. Chong, H.; Yusoff, N.A.; Hor, Y.Y.; Lew, L.C.; Jaafar, M.; Choi, S.-B.; Yusoff, M.; Wahid, N.; Bin Abdullah, M.F.I.L.; Zakaria, N.; et al. Lactobacillus plantarum DR7 alleviates stress and anxiety in adults: A randomised, double-blind, placebo-controlled study. Benef. Microbes 2019, 10, 355-373. [CrossRef] [PubMed]

57. Culpepper, T.; Christman, M.; Nieves, J.C.; Specht, G.; Rowe, C.; Spaiser, S.; Ford, A.; Dahl, W.; Girard, S.; Langkamp-Henken, B. Bifidobacterium bifidum R0071 decreases stress-associated diarrhoea-related symptoms and self-reported stress: A secondary analysis of a randomised trial. Benef. Microbes 2016, 7, 327-336. [CrossRef]

58. Hughes, C.; Davoodi-Semiromi, Y.; Colee, J.C.; Culpepper, T.; Dahl, W.J.; Mai, V.; Christman, M.C.; Langkamp-Henken, B. Galactooligosaccharide supplementation reduces stress-induced gastrointestinal dysfunction and days of cold or flu: A randomized, double-blind, controlled trial in healthy university students. Am. J. Clin. Nutr. 2011, 93, 1305-1311. [CrossRef]

59. Karbownik, M.S.; Kręczyńska, J.; Kwarta, P.; Cybula, M.; Wiktorowska-Owczarek, A.; Kowalczyk, E.; Pietras, T.; Szemraj, J. Effect of Supplementation with Saccharomyces Boulardii on Academic Examination Performance and Related Stress in Healthy Medical Students: A Randomized, Double-Blind, Placebo-Controlled Trial. Nutrients 2020, 12, 1469. [CrossRef] [PubMed]

60. Kato-Kataoka, A.; Nishida, K.; Takada, M.; Suda, K.; Kawai, M.; Shimizu, K.; Kushiro, A.; Hoshi, R.; Watanabe, O.; Igarashi, T. Fermented milk containing Lactobacillus casei strain Shirota prevents the onset of physical symptoms in medical students under academic examination stress. Benef. Microbes 2016, 7, 153-156. [CrossRef] 
61. Kato-Kataoka, A.; Nishida, K.; Takada, M.; Kawai, M.; Kikuchi-Hayakawa, H.; Suda, K.; Ishikawa, H.; Gondo, Y.; Shimizu, K.; Matsuki, T.; et al. Fermented Milk Containing Lactobacillus casei Strain Shirota Preserves the Diversity of the Gut Microbiota and Relieves Abdominal Dysfunction in Healthy Medical Students Exposed to Academic Stress. Appl. Environ. Microbiol. 2016, 82, 3649-3658. [CrossRef]

62. Kitaoka, K.; Uchida, B.K.; Okamoto, B.N.; Chikahisa, S.; Miyazaki, M.T.; Takeda, E.; Séi, H. Fermented Ginseng Improves the First-Night Effect in Humans. Sleep 2009, 32, 413-421. [CrossRef]

63. Kelly, J.; Allen, A.P.; Temko, A.; Hutch, W.; Kennedy, P.J.; Farid, N.; Murphy, E.; Boylan, G.; Bienenstock, J.; Cryan, J.F.; et al. Lost in translation? The potential psychobiotic Lactobacillus rhamnosus (JB-1) fails to modulate stress or cognitive performance in healthy male subjects. Brain Behav. Immun. 2017, 61, 50-59. [CrossRef]

64. Kiecolt-Glaser, J.K.; Belury, M.A.; Andridge, R.; Malarkey, W.B.; Glaser, R. Omega-3 supplementation lowers inflammation and anxiety in medical students: A randomized controlled trial. Brain Behav. Immun. 2011, 25, 1725-1734. [CrossRef] [PubMed]

65. Liu, Y.-W.; Liong, M.T.; Chung, Y.-C.E.; Huang, H.-Y.; Peng, W.-S.; Cheng, Y.-F.; Lin, Y.-S.; Wu, Y.-Y.; Tsai, Y.-C. Effects of Lactobacillus plantarum PS128 on Children with Autism Spectrum Disorder in Taiwan: A Randomized, Double-Blind, PlaceboControlled Trial. Nutrients 2019, 11, 820. [CrossRef] [PubMed]

66. Ba, B.E.M.; Bravender, T.D.; Harrison, T.M.; Lange, H.L.H.L.; Cottrill, C.B.; Abdel-Rasoul, M.; Bonny, A.E. A pilot randomized controlled trial of omega-3 fatty acid supplementation for the treatment of anxiety in adolescents with anorexia nervosa. Int. J. Eat. Disord. 2018, 51, 1367-1372. [CrossRef]

67. Papalini, S.; Michels, F.; Kohn, N.; Wegman, J.; van Hemert, S.; Roelofs, K.; Arias-Vasquez, A.; Aarts, E. Stress matters: Randomized controlled trial on the effect of probiotics on neurocognition. Neurobiol. Stress 2019, 10, 100141. [CrossRef] [PubMed]

68. Schmidt, K.; Cowen, P.; Harmer, C.; Tzortzis, G.; Errington, S.; Burnet, P.W.J. Prebiotic intake reduces the waking cortisol response and alters emotional bias in healthy volunteers. Psychopharmacology 2015, 232, 1793-1801. [CrossRef]

69. Tran, N.; Zhebrak, M.; Yacoub, C.; Pelletier, J.; Hawley, D. The gut-brain relationship: Investigating the effect of multispecies probiotics on anxiety in a randomized placebo-controlled trial of healthy young adults. J. Affect. Disord. 2019, 252, $271-277$. [CrossRef]

70. Capitão, L.P.; Baião, R.; Baek, H.K.; Kappelmann, N.; Sharman, R.; Harvey, C.-J.; Montgomery, P.; Burnet, P.W. Prebiotic Supplementation Does Not Affect Reading and Cognitive Performance in Children: A Randomised Placebo-Controlled Study. J. Psychopharmacol. 2020, 34, 148-152. [CrossRef]

71. Nova, E.; Alvarez, A.; Marcos, A.; Warnberg, J.; Gómez-Martínez, S.; Alvarez, R.; Mateos, J.A.; Cobo, J.M. The effect of milk fermented by yogurt cultures plus Lactobacillus casei DN-114001 on the immune response of subjects under academic examination stress. Eur. J. Nutr. 2004, 43, 381-389. [CrossRef]

72. Vijay, A.; Astbury, S.; Le Roy, C.; Spector, T.D.; Valdes, A.M. The prebiotic effects of omega-3 fatty acid supplementation: A six-week randomised intervention trial. Gut Microbes 2021, 13, 1863133. [CrossRef]

73. Kim, H.J.; Kim, P.; Shin, C.Y. A comprehensive review of the therapeutic and pharmacological effects of ginseng and ginsenosides in central nervous system. J. Ginseng Res. 2013, 37, 8-29. [CrossRef]

74. Bos, D.J.; Oranje, B.; Veerhoek, E.S.; Van Diepen, R.M.; Weusten, J.M.; Demmelmair, H.; Koletzko, B.; van der Velden, M.G.D.S.; Eilander, A.; Hoeksma, M.; et al. Reduced Symptoms of Inattention after Dietary Omega-3 Fatty Acid Supplementation in Boys with and without Attention Deficit/Hyperactivity Disorder. Neuropsychopharmacology 2015, 40, 2298-2306. [CrossRef] [PubMed]

75. Capitão, L.P.; Forsyth, J.; Thomaidou, M.; Condon, M.D.; Harmer, C.J.; Burnet, P.W. A single administration of 'microbial' D-alanine to healthy volunteers augments reaction to negative emotions: A comparison with D-serine. J. Psychopharmacol. 2020, 34, 557-566. [CrossRef] [PubMed]

76. Cornu, C.; Mercier, C.; Ginhoux, T.; Masson, S.; Mouchet, J.; Nony, P.; Kassai, B.; Laudy, V.; Berquin, P.; Franc, N.; et al. A double-blind placebo-controlled randomised trial of omega-3 supplementation in children with moderate ADHD symptoms. Eur. Child Adolesc. Psychiatry 2018, 27, 377-384. [CrossRef] [PubMed]

77. Karr, J.E.; Grindstaff, T.R.; Alexander, J.E. Omega-3 polyunsaturated fatty acids and cognition in a college-aged population. Exp. Clin. Psychopharmacol. 2012, 20, 236-242. [CrossRef] [PubMed]

78. Kennedy, D.O.; Jackson, P.A.; Elliott, J.M.; Scholey, A.B.; Robertson, B.C.; Greer, J.; Tiplady, B.; Buchanan, T.; Haskell, C.F. Cognitive and mood effects of 8 weeks' supplementation with $400 \mathrm{mg}$ or $1000 \mathrm{mg}$ of the omega- 3 essential fatty acid docosahexaenoic acid (DHA) in healthy children aged 10-12 years. Nutr. Neurosci. 2009, 12, 48-56. [CrossRef] [PubMed]

79. Milte, C.M.; Parletta, N.; Buckley, J.D.; Coates, A.M.; Young, R.; Howe, P. Eicosapentaenoic and docosahexaenoic acids, cognition, and behavior in children with attention-deficit/hyperactivity disorder: A randomized controlled trial. Nutrients 2012, 28, 670-677. [CrossRef]

80. Milte, C.M.; Parletta, N.; Buckley, J.D.; Coates, A.M.; Young, R.; Howe, P.R.C. Increased Erythrocyte Eicosapentaenoic Acid and Docosahexaenoic Acid Are Associated with Improved Attention and Behavior in Children with ADHD in a Randomized Controlled Three-Way Crossover Trial. J. Atten. Disord. 2013, 19, 954-964. [CrossRef]

81. Widenhorn-Müller, K.; Schwanda, S.; Scholz, E.; Spitzer, M.; Bode, H. Effect of supplementation with long-chain w-3 polyunsaturated fatty acids on behavior and cognition in children with attention deficit/hyperactivity disorder (ADHD): A randomized placebo-controlled intervention trial. Prostaglandins Leukot. Essent. Fat. Acids 2014, 91, 49-60. [CrossRef] 
82. Portillo-Reyes, V.; Pérez-García, M.; Loya-Méndez, Y.; Puente, A.E. Clinical significance of neuropsychological improvement after supplementation with omega-3 in 8-12 years old malnourished Mexican children: A randomized, double-blind, placebo and treatment clinical trial. Res. Dev. Disabil. 2014, 35, 861-870. [CrossRef]

83. Richardson, A.J.; Burton, J.R.; Sewell, R.P.; Spreckelsen, T.F.; Montgomery, P. Docosahexaenoic Acid for Reading, Cognition and Behavior in Children Aged 7-9 Years: A Randomized, Controlled Trial (The DOLAB Study). PLoS ONE 2012, 7, e43909. [CrossRef]

84. Steenbergen, L.; Sellaro, R.; Van Hemert, S.; Bosch, J.A.; Colzato, L.S. A randomized controlled trial to test the effect of multispecies probiotics on cognitive reactivity to sad mood. Brain Behav. Immun. 2015, 48, 258-264. [CrossRef] [PubMed]

85. Vesco, A.T.; Young, A.S.; Arnold, L.E.; Fristad, M.A. Omega-3 supplementation associated with improved parent-rated executive function in youth with mood disorders: Secondary analyses of the omega 3 and therapy (OATS) trials. J. Child Psychol. Psychiatry 2017, 59, 628-636. [CrossRef] [PubMed]

86. Voigt, R.G.; Llorente, A.M.; Jensen, C.L.; Fraley, J.; Berretta, M.C.; Heird, W.C. A randomized, double-blind, placebo-controlled trial of docosahexaenoic acid supplementation in children with attention-deficit/hyperactivity disorder. J. Pediatr. 2001, 139, 189-196. [CrossRef] [PubMed]

87. Marx, W.; Scholey, A.; Firth, J.; D'cunha, N.M.; Lane, M.; Hockey, M.; Ashton, M.M.; Cryan, J.F.; O'neil, A.; Naumovski, N.; et al. Prebiotics, probiotics, fermented foods and cognitive outcomes: A meta-analysis of randomized controlled trials. Neurosci. Biobehav. Rev. 2020, 118, 472-484. [CrossRef] [PubMed]

88. Faber, G.; Wolpert, M.; Kemmer, D. Common Measures for Mental Health Science: Laying the Foundations; NIH: London, UK, 2020.

89. Patalay, P.; Fried, E.I. Editorial Perspective: Prescribing measures: Unintended negative consequences of mandating standardized mental health measurement. J. Child Psychol. Psychiatry 2021, 62, 1032-1036. [CrossRef] 